\title{
ESTRATIGRAFIA E EVOLUÇÃO SEDIMENTAR DE DIAMICTITOS E CARBONATOS NEOPROTEROZÓICOS NO DOMÍNIO VAZA-BARRIS, FAIXA DE DOBRAMENTOS SERGIPANA, NORDESTE DO BRASIL.
}

\author{
Alexandre Uhlein ${ }^{1}$, Guilherme Labaki Suckau ${ }^{1}$, Julio Carlos Destro Sanglard ${ }^{1}$, Fabrício \\ Andrade Caxito ${ }^{1}$.
}

\begin{abstract}
RESUMO: A faixa de dobramentos neoproterozóica Sergipana ocorre no limite nordeste do Cráton do São Francisco. Este trabalho apresenta dados estratigráficos e sedimentológicos sobre diamictitos e carbonatos, metassedimentos do Domínio Vaza-Barris, Faixa Sergipana. As rochas metassedimentares da porção centro-sul da Faixa Sergipana (domínio Vaza-Barris) são subdividas nos Grupos Miaba (Formações Itabaiana, Jacarecica e Jacoca) e Vaza-Barris (Formações Capitão-Palestina, Olhos d'Água e Frei PauloRibeirópolis). Na região de Pinhão-Pedra Mole (SE), mapeada em detalhe, ocorrem boas exposições das Formações Capitão-Palestina e Olhos d'Água, ao longo do flanco normal do anticlinório de Pinhão. Metadiamictito, metagrauvaca, metarenito arcosiano maciço e metapelito laminado formam a associação de fácies da Fm. Capitão-Palestina, representando sedimentação marinha gravitacional, com fluxos de detritos. Metacalcarenito com estratificação cruzada/truncada de baixo ângulo (hummocky) e metacalcilutito formam a associação de fácies da Fm. Olhos d'Água, representando sedimentação carbonática de retrabalhamento, com fácies de tempestitos. O Grupo Vaza-Barris constitui-se numa sequência deposicional tipo 1, depositada discordantemente sobre o Grupo Miaba, apresentando os três tratos de sistemas principais: (1) trato de mar baixo - constituído por fluxos de detrito/lama em sistema deposicional marinho profundo; (2) trato transgressivo - rampa carbonática retrogradante; (3) trato de mar alto - depósitos silicilásticos progradacionais de sistema deposicional marinho raso.
\end{abstract}

Palavras-chave: Estratigrafia de sequências, Faixa Sergipana, Neoproterozóico, tratos e sistemas deposicionais, fluxos gravitacionais.

\begin{abstract}
STRATIGRAPHY AND SEDIMENTARY EVOLUTION OF NEOPROTEROZOIC DIAMICTITES AND CARBONATES IN THE VAZA BARRIS DOMAIN, SERGIPANA FOLD BELT, NORTHEASTERN BRAZIL. The Neoproterozoic Sergipano Fold Belt occurs on the northeastern margin of the Sao Francisco Craton. This study presents stratigraphic and sedimentologic data about the metasedimentary framework of the Vaza-Barris Domain, Sergipano Fold Belt. The metasedimentary rocks of this belt in central-southern portion occur into Vaza-Barris Domain and are subdivided into the following groups: Miaba (Itabaiana, Jacarecica and Jacoca formations) and Vaza-Barris (Capitão-Palestina, Olhos d'Água e Frei Paulo-Ribeirópolis formations). In the Pinhão-Pedra Mole (Sergipe) region, mapped in detail, there are good exposures of Capitão-Palestina and Olhos d'Água formations on the normal limb of Pinhao anticlinorium. Massive metadiamictites, massive metagraywackes and arkosean meta-arenites, laminated metapelites and metarhythmites form the facies association of the Capitão-Palestina Formation, representing mainly a gravitational marine sedimentation with debris flows. Metacalcarenites with low-angle cross/truncated bedding, metacalcilutites with plannar lamination and massive metacalcarenite form the facies association of the Olhos d'Água Formation, representing a reworked carbonatic sedimentation with tempestite facies. The Vaza Barris Group is a type 1 depositional sequence, unconformably resting upon the Miaba Group, with the three main system tracts: (1) low sea-level tract - with debris / mud flows in a deep marine environment; (2) transgressive tract - retrograding carbonatic ramp; (3) high sea-level tract - prograding siliciclastics in a shallow marine environment.
\end{abstract}

Keywords: Sequence stratigraphy, Sergipano Fold Belt, Neoproterozoic, depositional tracts and systems, gravitational flows.

\section{INTRODUÇÃO}

A Faixa de Dobramentos Sergipana constitui-se numa região orogênica neoproterozóica, formada durante o ciclo Brasiliano/Pan-Africano ( $600-540 \mathrm{Ma})$, e que ocorre ao sul do Maciço Pernambuco-Alagoas, no limite nordeste do Cráton do São Francisco (Almeida, 1977; Brito Neves et al, 2000). Geograficamente, esta faixa abrange grande parte do Estado de Sergipe, além do norte da Bahia e sul de Alagoas.
O objetivo deste trabalho é apresentar dados estratigráficos e sedimentológicos para metassedimentos do Domínio Vaza-Barris, metadiamictitos e metacalcários, que afloram na porção centro-sul da Faixa Sergipana. Pretende-se fazer a caracterização de litofácies, proposição de sistemas deposicionais e evolução estratigráfica baseada em estratigrafia de seqüências. Diamictitos neoproterozóicos são rochas sedimentares de origem glacial ou geradas por fluxos gravitacionais (fluxos de detritos) em ambientes 
não glaciais (Dott Jr., 1983; Eyles \& Januszczac, 2004), enquanto que carbonatos são depositados em plataformas marinhas de clima quente (Miall, 1984; Burchette e Wright, 1992). No Neoproterozóico estas rochas ocorrem frequentemente intercaladas, sugerindo freqüentes mudanças climáticas (Kennedy et al, 1998). Uma teoria denominada snow ball earth foi formulada (Kirschvink, 1992; Hoffman et al, 1998) tentando melhor explicar a origem e evolução destas rochas. A Faixa Sergipana, domínio Vaza-Barris, mostra alternâncias de diamictitos e carbonatos e constitui-se em excelente área para estudo destas rochas enigmáticas.

\section{PRINCIPAIS TRABALHOS ANTERIORES NA PORÇAO SUL DA FAIXA SERGIPANA}

A Faixa Sergipana pode ser subdivida em seis domínios litotectônicos. De sul para norte, são denominados de Estância, Vaza-Barris, Macururé, Marancó, Poço Redondo e Canindé (Silva Filho et al., 1979; Davison e Santos, 1989; Santos et al., 1998; D’elRey Silva, 1999; Oliveira et al, 2010). Estes domínios apresentam características estruturais, metamórficas e litoestratigráficas distintivas, justapostos por tectônica compressiva vergente para sudoeste, relacionada ao ciclo Brasiliano, na forma de falhas e zonas de cisalhamento de médio a alto ângulo (Fig.1).

Ao sul, ocorre o Domínio Estância, constituído por gnaisses do embasamento do Cráton do São Francisco e por rochas sedimentares subhorizontais, onde predominam os arenitos da Formação Lagarto.

No Domínio Vaza-Barris, o embasamento cristalino arqueano / paleoproterozóico aflora nos domos gnáissicos-migmatíticos de Itabaiana e Simão Dias.
As sequências metassedimentares neoproterozóicas podem ser divididas, da base para o topo, nos Grupos Miaba e Vaza-Barris (Humphrey e Allard, 1969; Silva Filho et al., 1979; D'el-Rey Silva, 1995, 1999, Sial et al, 2010). Inicialmente, Humphrey e Allard (1969), a partir de mapeamentos geológicos de detalhe, subdividiram o Grupo Miaba nas Formações Itabaiana, Jacarecica e Jacoca e o Grupo Vaza-Barris nas Formações Capitão, Palestina, Olhos d'Água, Frei Paulo e Ribeirópolis.

Posteriormente, considerando a dificuldade em mapear estas rochas em escala regional, Silva Filho et al (1979) propuseram a junção das Formações Capitão e Palestina em uma única unidade estratigráfica, designada Formação Capitão-Palestina e o mesmo foi proposto para as Formações Frei Paulo e Ribeirópolis, reunidas, então, numa mesma formação. No domínio Vaza-Barris predominam estruturas de um fold-andthrust belt, com duas superfícies de foliações $\mathrm{S}_{1}$ e $\mathrm{S}_{2}$, onde a segunda foliação é a superficie predominante, plano-axial dos principais dobramentos observados. A foliação $S_{2}$ mostra orientação WNW-ESE (100-110 $\mathrm{Az}$ ) e mergulhos fortes, variando de 50 a 70 para NE. Falhas inversas sin a pós- $\mathrm{S}_{2}$ são freqüentes (Fig.1). O metamorfismo é de fácies xisto verde. Destaca-se, a estrutura do Anticlinório de Pinhão, uma dobra assimétrica de grande porte, com cerca de $25 \mathrm{Km}$, recortada por falhas inversas (Humphrey \& Allard, 1969; Campos Neto \& Brito Neves, 1987; Jardim de Sá et al, 1986; D’el - Rey, 1995).

D’el-Rey Silva (1995, 1999), D’el-Rey Silva \& McClay (1995) propõem o Grupo Simão Dias, uma unidade posicionada entre os Grupos Miaba e VazaBarris, constituído pelas Formações Lagarto-Palmares (metarenito-metargilito), Jacaré (metassiltitos) e Frei Paulo (quartzitos e filitos). Recentemente, dados

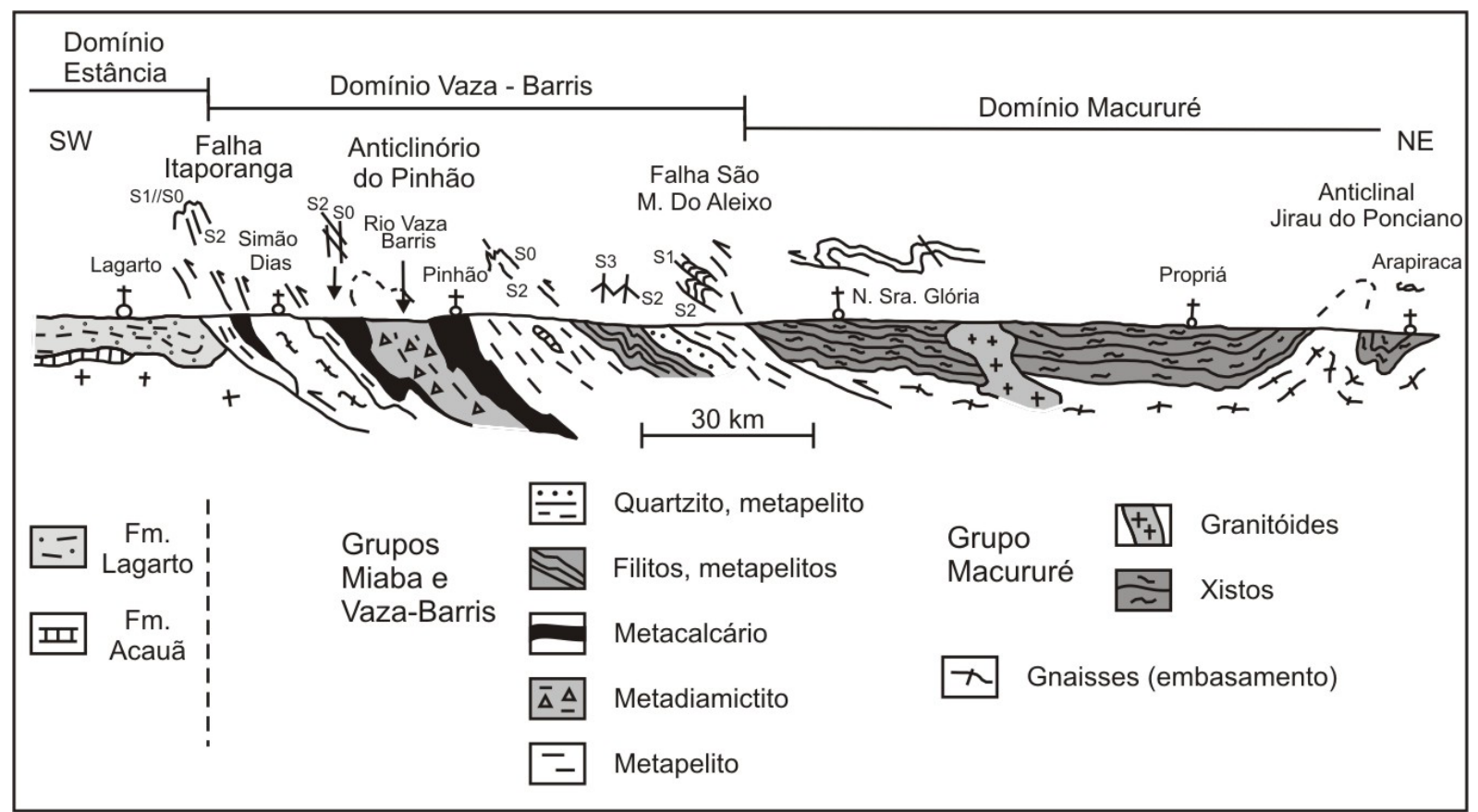

Figura 1 - Seção estrutural da porção centro-sul da Faixa Sergipana, com indicação dos domínios litotectônicos. Modificada de Campos Neto e Brito Neves (1987). 
geocronológicos de Oliveira et al (2005, 2006, 2010), baseados em U-Pb em zircão detrítico, indicaram significativas diferenças de idades de sedimentação, impossibilitando a aplicação da coluna estratigráfica de D'el-Rey Silva \& McClay (1995).

Sial et al (2010), baseados em Silva Filho et al (1979) e dados geocronológicos recentes (Oliveira et $a l, 2005,2006,2010)$, adotam esquema estratigráfico semelhante ao de Humphrey \& Allard, (1969) para a Faixa Sergipana, com o Grupo Miaba, subdividido nas Formações Itabaiana, Ribeirópolis /Jacaracica (com idade de $730 \mathrm{Ma}, \mathrm{U}-\mathrm{Pb}$ em metatufo ácido) e Jacoca. O Grupo Vaza Barris, subdividido nas Formações CapitãoPalestina, Olhos d'Àgua e Frei Paulo-Ribeirópolis (idade $<610 \mathrm{Ma}$, U-Pb em zircão detrítico, conforme Oliveira et al., 2005). No topo, colocam o Grupo Simão Dias, com as Formações Lagarto-Palmares (idade < $565 \mathrm{Ma}$, conforme Oliveira et al., 2005, 2010) e Jacaré.

No presente trabalho, segue-se a linha de nomenclatura litoestratigráfica proposta por Humphrey \& Allard (1969), modificada por Silva Filho et al. (1979) \& Sial et al (2010), ou seja, Grupo Miaba na base (metassedimentos pouco espessos ao redor dos domos) e Grupo Vaza-Barris (metassedimentos espessos superpostos ao Grupo Miaba).

A Formação Itabaiana (20 até 600 metros de espessura), base do Grupo Miaba (Fig.2), é constituída por quartzitos de granulometria média a grosseira, mostrando frequentes estratificações cruzadas (Fig. 4A) e raras intercalações de metaconglomerados e metapelitos.
Representam sedimentação fluvial, do tipo entrelaçado. As Formações Jacarecica (metadiamictito, metagrauvaca e filito) e Jacoca (carbonatos), com cerca de 200 - $300 \mathrm{~m}$ de espessura, representam, possivelmente, um sistema deposicional de fan-delta, com possível contribuição glacial.

O Grupo Vaza-Barris (Fig.2), com espessura de 2 a $4 \mathrm{~km}$, ocorre estratigraficamente acima, geralmente em contato tectônico, subdividido, da base para o topo, nas Formações Capitão-Palestina (metadiamictitos), Olhos d'Água (metacarbonatos) \& Frei Paulo-Ribeirópolis (metassiltitos e filitos), conforme Humphrey \& Allard (1969), Silva Filho et al. (1979) e Sial et al (2010).

O Grupo Macururé (Fig. 2) é constituído por mica-xistos granatíferos, metaritmitos, quartzitos, calcissilicáticas, e paragnaisses ocorrendo sobreposto ao Grupo Vaza-Barris, por contato tectônico (Falha de São Miguel do Aleixo; Fig. 1). Aflora ao norte do Estado de Sergipe, com grande extensão regional. Pode representar a continuidade estratigráfica da base do Grupo Vaza-Barris (Fig.2), com sedimentação turbidítica expressiva (Fig. 4 E).

\section{FÁCIES SEDIMENTARES E SISTEMAS DEPOSICIONAIS DA REGIÃO DE PINHÃO- PEDRA MOLE, DOMÍNIO VAZA BARRIS (SERGIPE)}

Na região dos municípios de Pinhão e Pedra Mole ocorrem boas exposições das formações CapitãoPalestina e Olhos d'Água, pertencentes ao Grupo

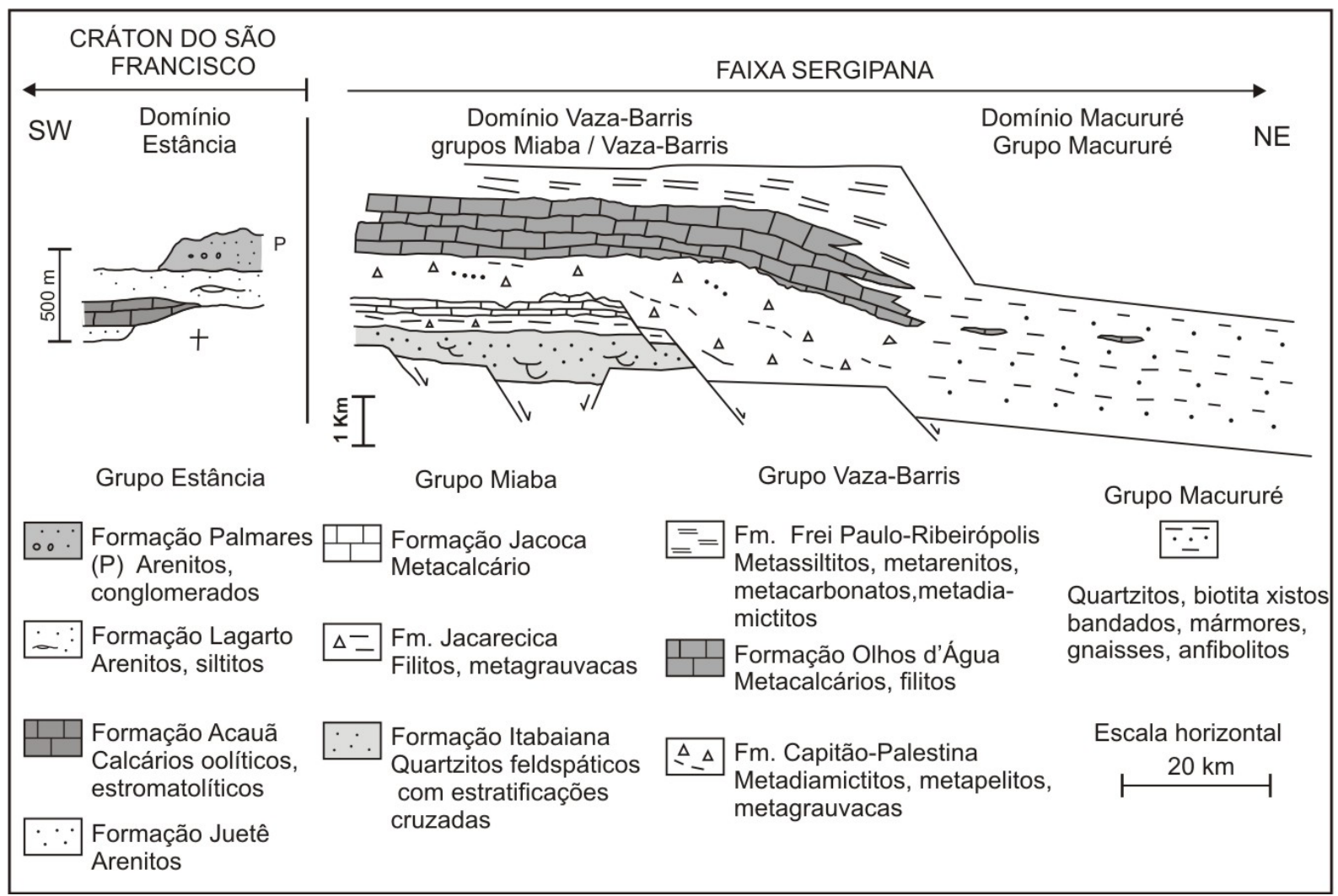

Figura 2 - Quadro estratigráfico para os Grupos Estância, Miaba, Vaza-Barris e Macururé, porção centro-sul da Faixa Sergipana. 
Vaza-Barris (Fig. 3). A região foi objeto de mapeamento geológico de detalhe, a fim de melhor caracterizar as litofácies e os sistemas deposicionais do Grupo VazaBarris. As rochas estão dispostas no flanco de uma megadobra assimétrica, designada de Anticlinório de Pinhão (Humphrey \& Allard, 1969).

A Formação Capitão-Palestina corresponde à unidade basal, ocorrendo na porção sul da cidade de Pinhão e nos arredores do Rio Vaza-Barris. Consiste predominantemente dos seguintes litotipos: metadiamictito (amplamente predominante), metapelito, metarenito arcosiano e metagrauvaca.

Os metadiamictitos (Fig. 4B) caracterizam-se por apresentarem uma matriz silto-argilosa cinzaesverdeada a arroxeada, às vezes arenosa, composta de sericita, muscovita, quartzo, pirita, carbonato e óxidos de alteração. O arcabouço polimítico inclui clastos de quartzito, granitóide, carbonato, quartzo e siltito, que variam de grânulo a matacão.

A abundância e tamanho dos clastos são variáveis, havendo porções com grânulos e seixos de até 5 $\mathrm{cm}$, dispersos em uma matriz silto-argilosa, que se intercalam com camadas de diamictitos com matriz areno-siltosa predominando seixos e calhaus, ou matacões.

Ocorrem planos de foliação $\mathrm{S}_{2}$ bem definidos e com estiramento dos clastos. Raramente é possível identificar planos de acamamento. A espessura da unidade é difícil de ser estimada, devido à repetições de camadas e dificuldades em se observar o acamamento. Entretanto, pode-se avaliar a espessura entre 1000 a 1500 metros.

Indicadores cinemáticos - clastos assimétricos com sombra de pressão - foram observados, principalmente por microscopia ótica (Fig. 4C).

Localmente, para o topo, ocorrem corpos lenticulares de metagrauvaca e metarenito arcosiano, maciços, de pequena espessura. Humphrey e Allard (1969) descrevem metagrauvaca laminada, com estratificação gradacional, associada aos metadiamictitos.

Nos arredores do Rio Vaza-Barris, afloram lentes de metapelito róseo a esverdeado que apresentam, localmente, laminação plano-paralela e ritmicidade, alternando lâminas silto-argilosas (sericita, muscovita, clorita, biotita e óxidos) e lâminas arenosas (quartzocarbonáticas).

A associação de fácies metadiamictito maciço, metagrauvaca e metarenito arcosiano maciços, metapelito laminado e metaritmito é interpretada como sendo depositada em um sistema deposicional marinho profundo, do tipo leque submarino, onde os diamictitos foram sedimentados a partir de fluxos gravitacionais subaquosos, de detrito/lama. Metagrauvacas com estratificação gradacional representam sedimentação turbidítica. Os corpos de metarenitos lenticulares intercalados podem representar sedimentação a

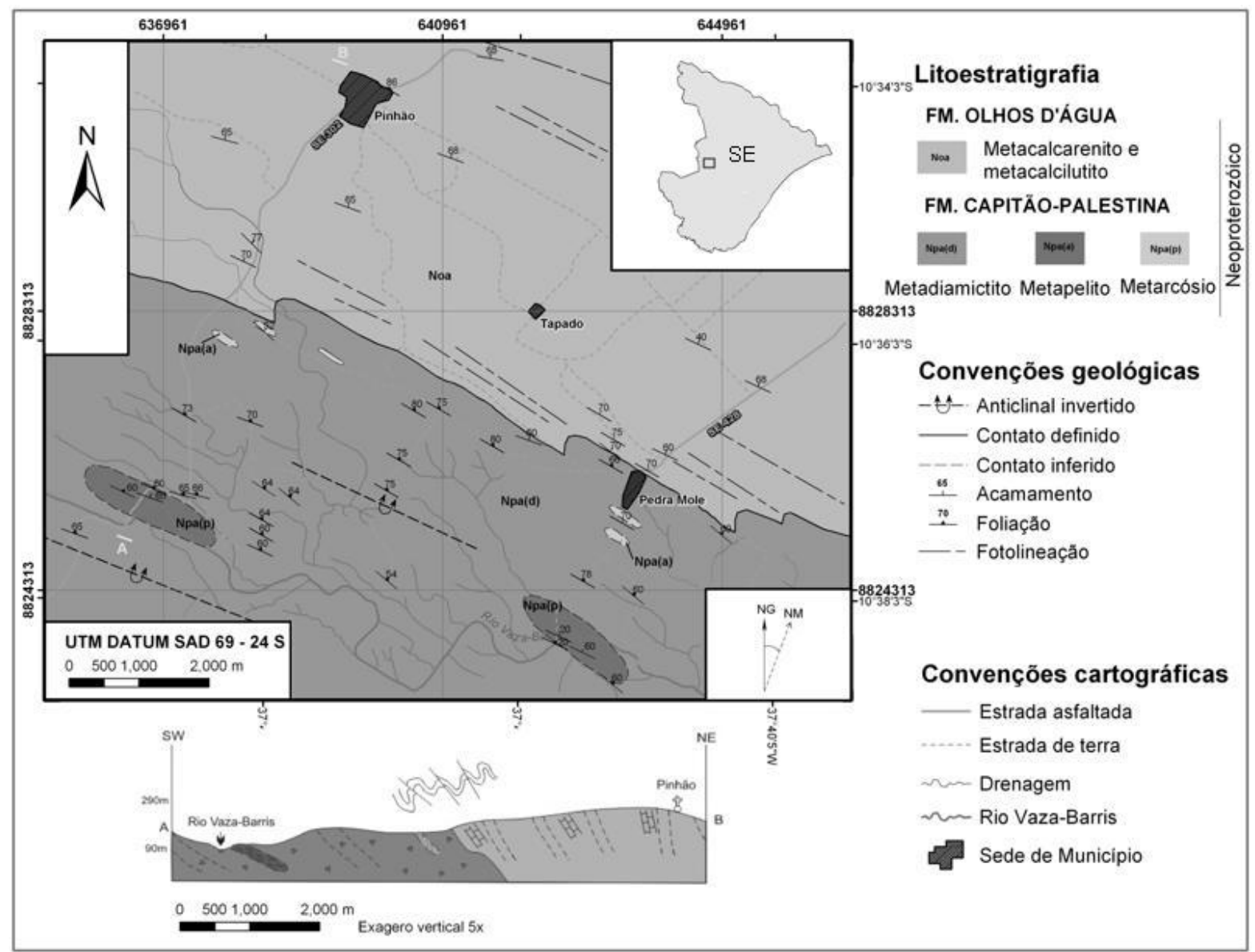

Figura 3 - Mapa geológico da região de Pinhão - Pedra Mole (Sergipe). 


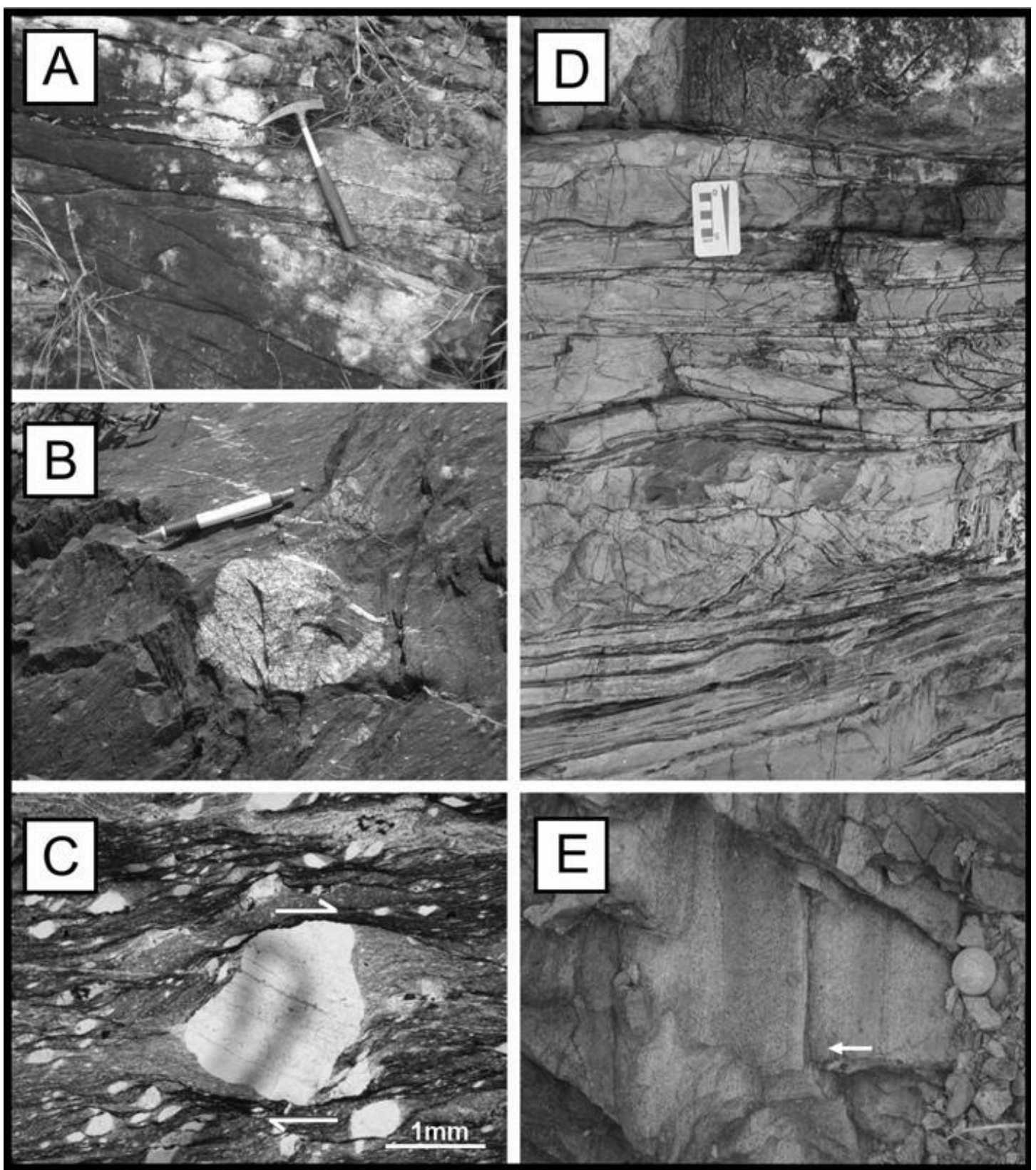

Figura 4 - A) Quartzito da Formação Itabaiana, com estratificação cruzada; B) Afloramento a sul de Pinhão, de metadiamictito maciço da Formação Capitão-Palestina exibindo calhau de granitóide em matriz silto-argilosa; C) Fotomicrografia de metadiamictito apresentando clasto lítico com sombras de pressão (indicador cinemático); D) Afloramento na região de Pinhão, intercalaçães de metacalcarenito e metacalcilutito exibindo laminações cruzadas/truncadas de baixo ângulo; E) Turbidito do Grupo Macururé, apresentando estratificação gradacional.

partir dos próprios fluxos gravitacionais ou correntes submarinas associadas, e os metapelitos representam a sedimentação por decantação nos períodos de calmaria, em porções mais distais e profundas.

A Formação Olhos d'Água está sobreposta à Fm. Capitão-Palestina através de contato brusco. Sugestões de dobras apertadas no contato foram identificadas por análise fotogeológica. A Formação Olhos D'Ägua constitui-se de intercalações (Fig. 4D) de metacalcarenito médio a fino, calcítico, maciço, de coloração cinza-azulada, e metacalcilutito, com laminação plano-paralela bem evidente.
Localmente foi possível observar estratificação cruzada/ truncada de baixo ângulo (hummocky). Veios de calcita branca de duas gerações comumente aparecem preenchendo fraturas.

O acamamento mostra direção correspondente ao trend tectônico regional $\left(\sim \mathrm{N} 70^{\circ} \mathrm{W}\right)$ e mergulho variável, entre cerca de 40 a $70^{\circ}$. A espessura máxima estimada gira em torno de 1300 metros. Nessa região, a associação de fácies metacalcarenito com estratificação cruzada/ truncada de baixo ângulo (hummocky), calcilutito com laminação plano-paralela e calcarenito maciço, é indicativa de fácies de tempestitos que ocorrem em 
ambiente plataformal, constituindo um sistema marinho de rampa carbonática de retrabalhamento, dominada por tempestades (mid-ramp, sensu Burchette \& Wright, 1992).

\section{ESTRATIGRAFIA E EVOLUÇAO SEDIMENTAR NO DOMINIO VAZA BARRIS, FAIXA SERGIPANA}

Através de mapeamento geológico e descrição de afloramentos importantes foi possível estabelecer a evolução de uma seqüência deposicional e seus respectivos tratos de sistemas para o Domínio Vaza Barris, região central da Faixa Sergipana (Fig.5).

Uma sequência deposicional corresponde a um ciclo completo de oscilação do nível do mar, e pode ser composta, da base para o topo em: 1) trato de sistemas de mar baixo; 2) trato de sistemas transgressivo; 3 ) Trato de sistemas de mar alto (Vail et al, 1977; Van Wagoner et al, 1988, Favera, 2001). Os tratos de sistemas são como um conjunto de sistemas deposicionais contemporâneos e geograficamente interligados. O trato de sistemas de mar baixo é depositado a partir de uma queda do nível do mar, quando a taxa de variação eustática supera a taxa de subsidência. Ocorrem vales fluviais incisos na plataforma, gerando discordância de borda de bacia e formam-se leques submarinos no talude/sopé. A linha de costa desloca-se em direção ao mar. O trato de sistemas transgressivo associa-se à taxa máxima de subida eustática, com migração da linha de costa em direção ao continente. Este trato é limitado pela superfície de inundação máxima e caracteriza-se por apresentar o afogamento do vale inciso, empilhamento estratigráfico retrogradacional e superfície de erosão por ondas. A superfície de inundação máxima separa o trato de sistemas transgressivo do trato de sistemas de mar alto. Houve, nesta fase, uma baixa taxa de sedimentação e a formação de horizontes ricos em matéria orgânica (folhelho negro), correspondendo, portanto, a um marco estratigráfico para correlação. O trato de sistemas de mar alto deposita-se com o lento abaixamento do nível do mar (regressão), mas principalmente quando a taxa de deposição (suprimento) é maior que a taxa de subida eustática que, por sua vez, reduz até um valor mínimo. Predomina uma arquitetura progradacional, com sedimentos costeiros se superpondo a sedimentos marinhos.

O Grupo Vaza-Barris representa uma sequência deposicional e apresenta os três tratos de sistemas, sugerindo um ciclo completo de oscilação do nível do mar (Fig. 5).

Os metadiamictitos da Fm. Capitão-Palestina, base da sequência deposicional, representam depósitos de fluxos de detrito/lama, sedimentados durante nível relativo do mar baixo. Os aspectos texturais (mistura de argila-silte até matacão) indicando pobre seleção, assim como a elevada espessura, intercalações de metapelitos laminados, permitem interpretar estas rochas como formadas por fluxos gravitacionais subaquosos, num sistema deposicional marinho profundo, do tipo leque submarino, sedimentados durante um trato de sistemas de mar baixo (Fig.5A). Os clastos presentes no metadiamictito indicam erosão de unidades mais antigas, no caso, os arenitos Itabaiana, pelitos Jacarecica e calcários Jacoca, assim como rochas granito-gnáissicas do embasamento.

Um possível evento glacial poderia ter ocasionado o rebaixamento do nível relativo do mar, expondo a plataforma da unidade inferior (Grupo Miaba), promovendo sua exposição e erosão, com conseqüente formação de uma discordância na borda da bacia. Seixos de metacarbonato e de quartzitos no metadiamictito sobreposto, indicam uma discordância erosiva. Alterações do tipo dolomitização, devido ao intemperismo químico (Humphrey \& Allard, 1969), identificada no metacarbonato Jacoca (Grupo Miaba), sugere exposição sub-aérea. A exposição da plataforma Miaba, a dolomitização e o retrabalhamento erosivo são indícios da existência de um limite de sequências do tipo 1 (discordância) entre os Grupos Miaba e Vaza-Barris. Além disto, um provável tectonismo extensional, com soerguimento e rebaixamento de blocos por ação de falhamentos normais (formando horsts e grabens), poderia também ter propiciado a instalação de rampas, favorecendo a sedimentação gravitacional, principalmente na porção proximal da bacia. A compartimentação da bacia por falhas normais, num modelo de extensão continental, foi sugerido, anteriormente, por Del Rey \& McClay (1995) para a Faixa Sergipana.

Dados quimioestratigráficos das rochas carbonáticas Jacoca e Olhos d'Água, obtidos por Sial et al. (2006, $2009,2010)$, mostram valores de $\delta^{13} \mathrm{C}$, compatíveis com carbonatos de capa (cap carbonates). Carbonatos de capa são rochas carbonáticas que ocorrem em contato com diamictitos glaciogênicos e representam sedimentação em contexto greenhouse (deglaciação), conforme Hoffman et al (1998) e Hoffman \& Schrag (2002). Existem três glaciações bem representadas no Neoproterozóico: Sturtiana (entre 750 a $700 \mathrm{Ma}$ ), Marinoana (entre 630 a $600 \mathrm{Ma}$ ) e Gaskiers (580 Ma), conforme Kennedy et al (1998). Dados de $\delta^{13} \mathrm{C}$ para o metacarbonato Olhos d'Água mostram flutuações dos valores, variando de negativas $(-5 \%)$ a positivas $(+8$ a $+10 \%$ ). Sial et al. (2010), a partir dos dados quimioestratigráficos, propõem que os metacarbonatos Olhos d'Água sejam carbonatos de capa. Oliveira et al. (2005), a partir de datações de U/Pb em zircões detríticos em metagrauvaca da Formação Frei PauloRibeirópolis obtiveram uma idade máxima de 630 Ma para a deposição dessa unidade. Assim sendo, a sedimentação do topo da Sequência Vaza-Barris deve ter ocorrido entre 600-610 Ma, sugerindo que o evento glacial responsável pelo rebaixamento do nível do mar tenha sido Marinoano. Dessa forma, os dados geocronológicos e quimioestratigráficos sugerem um evento glacial Marinoano ( 630-620 Ma), parcialmente sincrônico à deposição dos diamictitos da Formação 


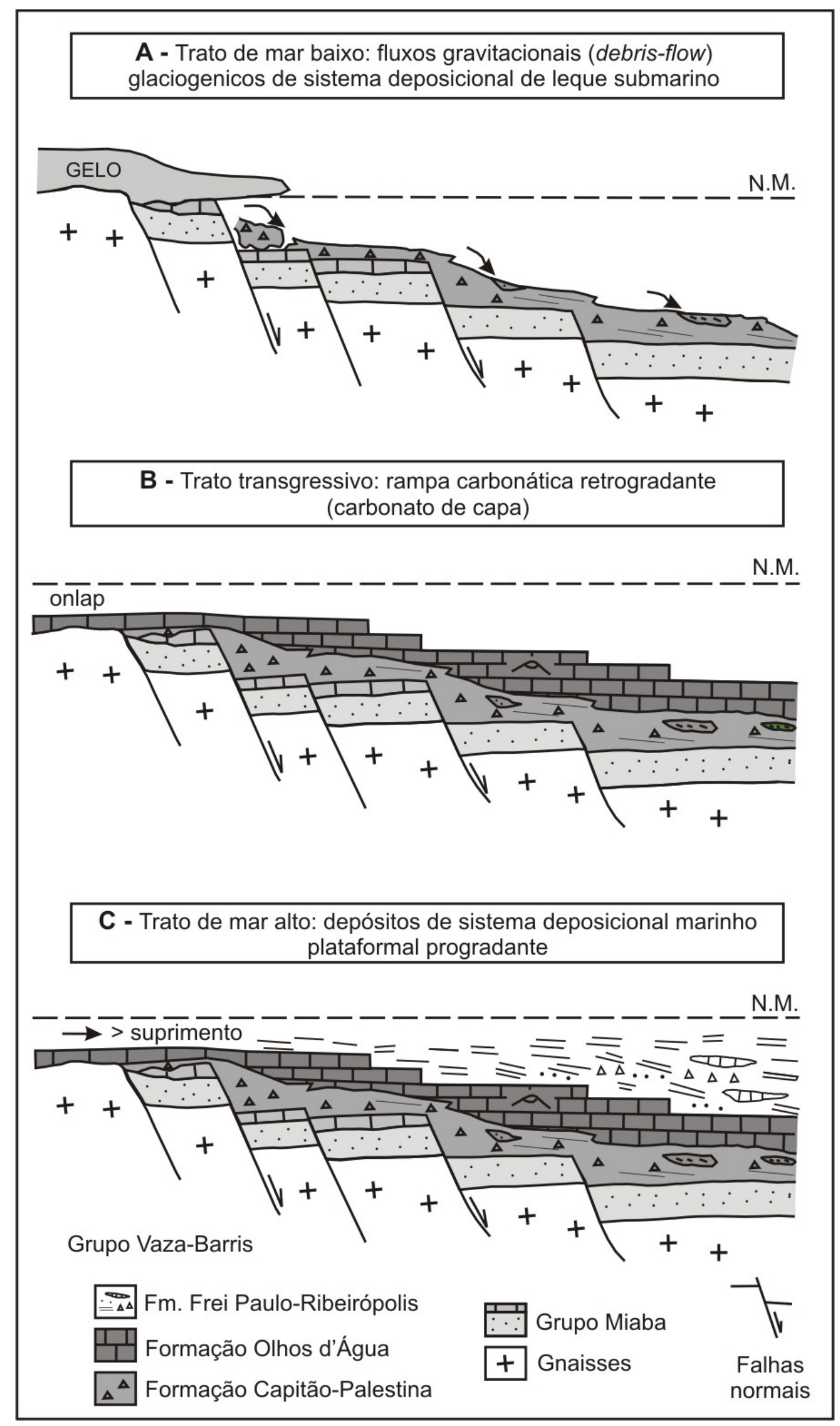

Figura 4-Modelo sedimentar e tratos deposicionais para a Sequência Vaza-Barris, Faixa Sergipana 
Capitão-Palestina (Sial et al, 2010). O registro desta glaciação poderia estar presente em algum local da cobertura cratônica, no Grupo Estância, na forma de tilitos (diamictitos) com pequena espessura, geralmente lenticulares.

Os metadiamictitos Capitão-Palestina, que mostram grande espessura e associação com litofácies marinhas, não representam tilitos sensu strictu. Porém, as litofácies identificadas e descritas neste trabalho, junto com os dados quimioestratigráficos de Sial et al (2010), indicam que os diamictitos representam fluxos gravitacionais glaciogênicos, em ambiente marinho. A glaciação Marinoana provavelmente levou a um rebaixamento do nível do mar que favoreceu a sedimentação de fluxos gravitacionais (avalanches), em borda de bacia (Fig. 5A). Neste caso, o manto de gêlo, ao invadir a plataforma continental gera diversos fluxos gravitacionais subaquosos, na forma de fluxos de detritos e lama, que formam os diamictitos. Sedimentos mais finos podem ocorrer interestratificados, resultantes da decantação de plumas de sedimentos ou correntes subaquosas de densidade (correntes de turbidez), gerando as demais litofácies associadas. Assim, a sedimentação do Trato de Mar Baixo envolveu diversos fluxos gravitacionais subaquosos, gerados em parte por um evento glacial regional, a glaciação Marinoana, como indicam os dados de Sial et al (2010).

Cabe aqui fazer referência aos debates sobre a hipótese Snowball Earth (Hoffman \& Schrag, 2002), francamente favorável a existência de glaciações globais e de Eyles \& Janusczak (2007), com posição contrária, enfatizando a origem não glacial de diamictitos, neste caso, depositados por fluxos gravitacionais. A Faixa Sergipana, devido às ótimas condições de afloramentos e presença de diamictitos em contato com carbonatos espessos, o que permite análises quimioestratigráficas importantes, pode ser um bom local para permitir modelos geológicos e estratigráficos alternativos.

A elevação do nível relativo do mar, durante um evento transgressivo, ocasionou o desenvolvimento de uma rampa carbonática (Fig.5B). Metacalcários bioquímicos estromatolíticos de águas rasas são descritos por Santos et al. (1998), e podem corresponder à rampa carbonática interna (inner ramp), dominada por marés. Os metacalcários de retrabalhamento são os registros dominantes na Faixa Sergipana, principalmente nos arredores de Pinhão (SE), representando depósitos de rampa carbonática média (mid ramp), dominada por tempestades. Os calcários bioquímicos, depositados em sistemas deposicionais litorâneo / marinho raso em rampa interna, seriam a área fonte dos sedimentos carbonáticos de retrabalhamento. Em suma, os metacarbonatos Olhos d'Água foram depositados em padrão retrogradante, constituindo um padrão tipo onlap costeiro, durante um trato de sistemas transgressivo. Formou-se então, uma plataforma carbonática tipo rampa, com sistemas deposicionais de águas rasas, incluindo sedimentação estromatolítica, predominando a sudoeste, e de águas mais profundas a nordeste (tempestitos). O aporte detrítico (suprimento) foi muito reduzido em função do evento transgressivo, favorecendo a sedimentação carbonática.

A instalação de um trato de sistemas de mar alto ocorreu logo após o estabelecimento do nível relativo do mar mais elevado, e sua estabilização (Fig. 5C). Nesta fase, o suprimento aumenta e ocorre a deposição em padrão agradacional, enquanto o nível do mar permanece estável, e progradacional, com o início lento da regressão. Associações das rochas metacarbonato, metadiamictito, metassiltito, filito, quartzito e metapelito carbonático da formação Frei Paulo-Ribeirópolis indicam um sistema deposicional marinho raso progradacional, com nível do mar diminuindo progressivamente, aumento do suprimento e retorno da sedimentação siliciclástica. As litofácies dominantes, metassiltitos, filitos e metarenitos sugerem sedimentação plataformal marinho raso.

\section{CONCLUSÕES.}

Análise das litofácies metassedimentares do Grupo Vaza-Barris indica uma sequência deposicional do tipo 1, formada por um conjunto de tratos de sistemas: mar baixo, transgressivo e mar alto, correspondentes, respectivamente às associações faciológicas das Formações Capitão-Palestina, Olhos d'Água e Frei Paulo-Ribeirópolis.

O trato de mar baixo é caracterizado pela deposição siliciclástica progradante (metadiamictitos, metarenitos arcosianos, metapelitos) em sistema deposicional marinho, a partir de fluxos gravitacionais de detritos/ lama, em contexto de leque submarino.

A sedimentação gravitacional subaquosa deve ter sido favorecida pelo evento glacial Marinoano. $\mathrm{O}$ trato transgressivo corresponde à formação de uma rampa carbonática homoclinal retrogradante, com sedimentação de calcários bioquímicos e de retrabalhamento.

Finalmente, o trato de mar alto é representado pelos depósitos siliciclásticos progradantes da Formação Frei Paulo-Ribeirópolis, em sistema deposicional marinho raso. Estudos adicionais são necessários para melhor situar a proveniência dos clastos dos metadiamictitos, baseados em estudos isotópicos e geocronológicos, visando melhor reconhecer o contexto bacinal da sedimentação neoproterozóica.

\section{AGRADECIMENTOS}

Os autores agradecem ao Conselho Nacional de Desenvolvimento Científico e Tecnológico (CNPq) pela concessão de bolsas de iniciação científica (IC) e de produtividade em Pesquisa (PQ) e à Fundação de Amparo à Pesquisa de Minas Gerais (FAPEMIG) pelo apoio financeiro dentro do projeto CRA 505-06. Ao Prof. Dr. Alcides Sial (UFPE) pelas discussões sobre a estratigrafia da Faixa Sergipana. 


\section{REFERÊNCIAS}

ALMEIDA, F.F.M.de 1977. O Cráton do São Francisco. Rev. Brás. Geociências, 7: 349-364.

BRITO NEVES, B. B.; SANTOS, E. J.; VAN SCHMUS, W. R. 2000. Tectonic History of the Borborema Province, Norheastern Brazil. In: CORDANI, U. G.; MILANI, E. J.; THOMAZ FILHO, A.; CAMPOS, D. A. (eds.) Tectonic Evolution of South America. Rio

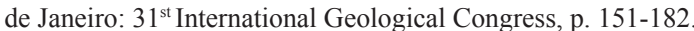

BURCHETTE, T. P.; WRIGHT, V. P. 1992. Carbonate ramp depositional systems. Sedimentary Geology, v. 79, p. 3-57.

CAMPOS NETO, M. C.; BRITO NEVES, B. B. 1987. Considerações sobre a organização e a geometria do sistema de dobramentos Sergipana. In: SIMPÓSIO NACIONAL DE ESTUDOS TECTÔNICOS, 1., 1987. Salvador. Bol. Resumo... Salvador: SBG, 1987, p. 90-93

DAVISON, I.; SANTOS, R. A. 1989. Tectonic Evolution of the Sergipano Fold Belt, NE Brazil, during the Brasiliano Orogeny. Precambrian Research, v. 45, p. 319-342.

D’EL-REY SILVA, L. J. H. 1995. Tectonic evolution of the Sergipano Belt, NE Brazil. Rev. Bras. Geociências. São Paulo, v. 25, p. 315-332.

D’EL-REY SILVA, L. J. H.; McCLAY, K. R. 1995. The Southern Part of the Sergipano Belt, NE Brazil: Stratigraphy and Tectonic Implications. Rev. Bras. Geociências. São Paulo, v. 25, p. 185202.

D’EL-REY SILVA, L. J. H. 1999. Basin infilling in the southerncentral part of the Sergipano Belt, NE Brazil, and implications for the tectonic evolution of the Pan-African/Brasiliano cratons and Neoproterozoic sedimentary cover. Journal of South American Earth Sciences, v. 12, p. 453-470.

DOTT JR., R. H. 1983. SEPM Presidential address: episodic sedimentation - How normal is average? How rare is rare? Does it matter?. Journal of Sedim. Petrol., v. 53, p. 5-23.

EYLES, N. \& JANUSZCZAC, N. 2004. 'Zipper-rift': a tectonic model for Neoproterozoic glaciations during the breakup of Rodinia after 750 Ma. Earth-Science Reviews, 65:1-73.

EYLES, N.; JANUSZCZAK, N. 2007. Syntectonic subaqueous massflows of the neoproterozoic Otavi Group, Namíbia: where is the evidence of global glaciation ? Basin Research, v.19, p. 179-198.

FÁVERA, J. C. D. 2001. Fundamentos de Estratigrafia Moderna. $1^{\text {a }}$ ed. Rio de Janeiro: Eduerj, 263 p.

HOFFMAN, P.F.; KAUFMAN, A.J.; HALVERSON, G.P.; SCHRAG, D.P. 1998. A neoproterozoic snowball Earth. Science, 281, 1342-46.

HOFFMAN, P, F. e SCHRAG, D.P. 2002. The snowball Earth hypothesis: testing the limits of global change. Terra Nova, 14: 129-155.

HUMPHREY, F. L.; ALLARD, G. O. 1969. Geologia da área do domo de Itabaiana (SE) e sua relação com a geologia do geossinclinal de Propriá - Um elemento tectônico recem-conhecido no Escudo Brasileiro. Tradução de MUNNE, A. I., BARÃO, S. C. Rio de Janeiro, PETROBRAS/CENPES, 1969, 157 p. il.: mapa.

JARDIM DE SÁ, E. F; MORAES, J. A. C.; D’EL-REY SILVA, L. J. H. 1986. Tectônica tangencial na Faixa Sergipana. In: CONGR. BRAS. DE GEOLOGIA, 34., 1986. Goiânia. Anais... Goiânia: SBG, 1986. p. 1246-1259.

KENNEDY, M.J.; RUNNEGAR,B.; PRAVE, A.R. HOFFMANN, K.H.; ARTHUR, M.A. 1998. Two or four neoproterozoic glaciations? Geology, 26 (12): 1059-1063.

KIRSCHVINK J.L., 1992, Late Proterozoic Low-Latitude Global Glaciation: The Snowball Earth. Section 2.3 in: J.W. Schopf, C. Klein, \& D. Des Maris (eds), The Proterozoic Biosphere: A Multidisciplinary Study. Cambridge University Press, pp. 51-52.

MIALL, A.D. 1984. Principles of Sedimentary Basin Analysis. $2^{\mathrm{a}}$ ed., New York, Springer Verlag, 409 p

OLIVEIRA, E. P.; CARVALHO, M. J.; NASCIMENTO, R. S.; MCNAUGHTON, N. 2005. Evolution of the Neoproterozoic Sergipano Orogenic Belt, NE Bazil: detrital zircon geochronology and $\mathrm{Sm} / \mathrm{Nd}$ isotopes on metasedimentary rocks unravel part of the story. In: SIMPÓSIO SOBRE O CRÁTON DO SÃO FRANCISCO, 3., 2005. Salvador. Short Papers... Salvador: SBG, 2005. p. 166-169.
OLIVEIRA, E. P.; TOTEU, S. F.; ARAÚJO, M. J.; CARVALHO, M. J.; NASCIMENTO, R. S.; BUENO, J. F.; MCNAUGHTON, N.; BASILICI, G. 2006. Geologic correlation between the Neoproterozoic Sergipano belt (NE Brazil) and the Yaoundé belt (Cameroon, Africa). Journal of African Earth Sciences, v. 44, p. 470-478.

OLIVEIRA, E. P., WINDLEY, B.F., ARAÚJO, M.N.C., 2010. The neoproterozoic sergipano orogenic belt, NE Brazil: a complete plate tectonic cycle in western Gondwana. Precambrian Research, 181: 64-84.

SANTOS, R. A.; MARTINS, A. A. M.; NEVES, J. P.; LEAL, R. A. (Org.). 1998. Geologia e recursos minerais do Estado de Sergipe. Brasília, CPRM/CODISE, 157 p. 1 mapa, col. Escala 1:250.000 (Programa Levantamentos Geológicos Básicos do Brasil - PLGB).

SIAL, A. N.; FERREIRA, V. P.; SILVA FILHO, M. A.; GAUCHER, C.; SOARES, D. R.; PIMENTEL, M. M.; LACERDA, D. L.; GANTOIS, G. 2006. Chemostratigraphy of two Neoproterozoic cap carbonates of the Sergipano belt (northeastern Brazil). In: SOUTH AMERICAN SYMPOSIUM ON ISOTOPE GEOLOGY, 5., 2006. Punta del Este. Short Papers..., Punta del Este: ALGU, 2006, p. 314-317.

SIAL, A. N.; DARDENNE, M. A.; MISI, A.; PEDREIRA, A.; FERREIRA, V. P.; SILVA FILHO, M. A.; UHLEIN, A.; PEDROSA-SOARES, A. C.; SANTOS, R. V.; EGYDIO-SILVA, M.; BABINSKI, M.; ALVARENGA, C. J. S.; PIMENTEL, M. M. The São Francisco Paleocontinent. Chapter 8. In: GAUCHER, C.; SIAL, A. N.; HALVERSON, G.; FRIMMEL, H. (orgs.). Neoproterozoic - Cambrian Tectonics, Global Change and Evolution: a Focus on Southwestern Gondwana. Londres: Elsevier, 2009.

SIAL, A.N.; GAUCHER, C.; SILVA FILHO, M.A.; FERREIRA, V.P.; PIMENTEL, M.M.; LACERDA, L.D.; EMMANOEL V.; SILVA FILHO, E.V.; CEZARIO, W. C- Sr-isotope and Hg chemostratigraphy of Neoproterozoic cap carbonates of the Sergipano Belt, Northeastern Brazil. Precambrian Research, 182: 351-372..

SILVA FILHO, M. A.; BOMFIM, L. F. C.; SANTOS, R. A.; LEAL, R. A.; SANTANA, A. C.; BRAZ FILHO, P. A. 1979. Geologia do Geossinclinal Sergipana e do seu embasamento. Alagoas, Sergipe e Bahia. Brasília, MME/DNPM, 131 p. 1 mapa, col. Escala 1:500.000 (Projeto Baixo São Francisco/Vaza Barris).

VAIL, P. R.; MITCHUM, R. M.; TODD, R. G.; WIDMIER, J. M.; THOMPSON, S. S.; SANGREE, J. B.; BUBB, J. N.; HATELID, W. G. 1977. Seismic stratigraphy and global changes of sea level. In: PAYTON, C. E. (eds.) Seismic Stratigraphy - Applications to Hidrocarbon Exploration. Tulsa: American Association of Petroleum Geologists, p. 49-205. (Memoir, 26)

VAN WAGONER, J. C.; POSAMENTIER, H. W.; MITCHUM, R. M.; VAIL, P. R.; SARG, J. F.; LOUTIT, T. S.; HARDENBOL, J. 1988. An overview of the fundamentals of sequence stratigraphy and key definitions. In: WILGUS, C. K.; HASTINGS, B. S.; KENDALL, C. G. ST. C.; POSAMENTIER, H.; ROSS, C. A.; VAN WAGONER, J. (eds.) Sea-level changes: an integrated approach.. Tulsa, Estados Unidos:SEPM, 1988. p. 39-45. (Society of Economic Paleontologists and Mineralogists Special Publication, 42). 